\title{
nursing students
}

Floreta KURTI, Tatjana CINA, Brizilda REFATLLARI, Vjollca SHPATA, Albana Gjyzari, Ermira BIU

University Hospital Center "Mother Theresa" Tirana, ALBANIA

Faculty of Medical Technical Sciencies, University of Medicine, Tirana, ALBANIA

\section{OBJECTIVES}

The aim of the study is to identify the current level of knowledge of nursing students at the end of their studies in the Master's degree about competence in general nursing, work accidents and competence of endocrine nurses in diabetes care.

\section{METHODS}

We had 673 nursing students enrolled in the study. They were all students at the end of their study in the master's degree. $76 \%$ of the students were practicing nurses with more than 3 years of work experience. All the students fulfilled a very detailed anonymous questionnaire about work accidents, prevention and post exposure prophylaxis, as well as specific knowledge on tests in relation to normal and abnormal organ function.

\section{RESULTS}

We had 108 males $(15.7 \%)$ and 567 females $(84.2 \%)$. Mean age of nursing students was $27.38 \pm 1.24$.

Out of 673 students, 580 of them $(86.18 \%)$ report that they had at least one work accident during their work experience.

102 nursing students $(15,15 \%)$ had good levels of knowledge about tests in relation to normal and abnormal organ function.

Only 38 nursing students (4.75\%) had expert level knowledge on the specialised field.

Mean years of work experience is significantly higher in nurses with expert level knowledge's, and this is statistically significant, $p<0.05$.

\section{CONCLUSIONS}

Even after Master studies, the level of knowledge of nurses about prevention of work accidents, post-exposure prophylaxis and competency in special nursing fields is unsatisfactory. These results raise the need for the development of national standards in general nursing and the need for professional accreditation of skills and knowledge into practice. We should focus on work-based and lifelong learning plus supervisionn. Specialist nurses may achieve the expert status, in those competencies relevant to them, after 5 years and more in their specialty.

\section{References}

1. Rozina Roshan Essani and Tazeen Saeed Ali, "Knowledge and Practice Gaps among Pediatric Nurses at a Tertiary Care Hospital Karachi Pakistan," ISRN Pediatrics, vol. 2011 Article ID 460818, 8 pages, 2011. doi: $10.5402 / 2011 / 460818$

2. M. Launders, "The theory/practice gap in nursing: the views of the students," Journal of Nursing and Midwifery, vol. 1, no. 4, pp. 142-147, 2001. 